\title{
Neurone-specific enolase levels in pleural effusions in patients with rheumatoid arthritis
}

\author{
Peter Nyberg, Terhi Söderblom, Tom Pettersson, Henrik Riska, Matti Klockars, \\ Linnéa Linko
}

\begin{abstract}
Background - High pleural fluid levels of neurone-specific enolase (NSE) have been reported, not only in patients with small cell lung cancer but also in those with chronic inflammatory diseases.

Methods - NSE concentrations were determined in pleural fluid and serum from 342 patients with pleural effusions including 17 with rheumatoid arthritis.

Results - The median NSE concentration in pleural fluid was higher in rheumatoid effusions than in any other condition studied. The median pleural fluid:serum NSE ratio was highest in patients with rheumatoid arthritis $(11 \cdot 6)$ and about unity in all other diseases including small cell lung cancer $(0.9)$. In patients with rheumatoid arthritis pleural fluid concentrations of NSE correlated inversely with pleural fluid glucose concentrations and the $\mathrm{pH}$ of the pleural fluid.

Conclusions - A high pleural fluid:serum NSE ratio was found consistently in pleural effusions from patients with rheumatoid disease.

(Thorax 1996;51:92-94)
\end{abstract}

Keywords: neurone-specific enolase, pleural effusion, rheumatoid arthritis.

Department of

Medicine

T Söderblom

T Pettersson

Department of Public Health

M Klockars

University of Helsinki, Finland

Correspondence to:

Dr P Nyberg.

Received 23 January 1995 Returned to authors 18 April 1995

Revised version received

12 June 1995

Accepted for publication

25 September 1995
Neurone-specific enolase (NSE) is a glycolytic enzyme which occurs mainly in neuronal and neuroendocrine cells. ${ }^{12}$ Many neuroendocrine tumours stain for NSE, and high serum levels occur in patients with small cell lung cancer. ${ }^{3}$

Raised concentrations of NSE in pleural fluid have been shown to differentiate pleural effusions due to small cell lung cancer from effusions of other origin, ${ }^{4}$ but increased concentrations of NSE in pleural fluid have also been reported in some chronic inflammatory diseases such as rheumatoid arthritis. ${ }^{5}$ We de-

Table 1 Pleural fluid concentrations of neurone-specific enolase (NSE) ( $\mu g / l)$ in rheumatoid pleural effusions compared with effusions of other aetiologies

\begin{tabular}{|c|c|c|c|c|c|}
\hline Diagnosis & $n$ & Median & Range & $95 \% C I$ & $p^{*}$ \\
\hline Rheumatoid arthritis & 17 & $56 \cdot 2$ & $12 \cdot 2-157 \cdot 8$ & $19 \cdot 3$ to $99 \cdot 4$ & \\
\hline Lung cancer & 52 & $6 \cdot 1$ & $1 \cdot 8-168 \cdot 8$ & 4.7 to 10.3 & $<0.0001$ \\
\hline Mesothelioma & 10 & $7 \cdot 6$ & $1 \cdot 3-52 \cdot 6$ & 2.9 to 40.7 & $<0.001$ \\
\hline Other cancers & 67 & 6.5 & $0-202 \cdot 0$ & 4.9 to 9.5 & $<0.0001$ \\
\hline SLE & 5 & $3 \cdot 3$ & $2 \cdot 5-12 \cdot 4$ & - & $<0.005$ \\
\hline Tuberculosis & 27 & $7 \cdot 1$ & $1 \cdot 6-116 \cdot 8$ & $3 \cdot 3$ to $12 \cdot 3$ & $<0.0001$ \\
\hline Parapneumonic effusions & 43 & 4.9 & $0 \cdot 5-31 \cdot 3$ & $3 \cdot 6$ to $7 \cdot 3$ & $<0.0001$ \\
\hline Other verified diagnoses & 22 & 3.9 & $1 \cdot 1-51 \cdot 7$ & $2 \cdot 3$ to $5 \cdot 1$ & $<0.0001$ \\
\hline Non-specific effusions & 72 & $5 \cdot 1$ & $1 \cdot 0-23 \cdot 0$ & $4 \cdot 3$ to $5 \cdot 6$ & $<0.0001$ \\
\hline Congestive heart failure & 27 & $2 \cdot 7$ & $1 \cdot 0-12 \cdot 0$ & $2 \cdot 0$ to $3 \cdot 2$ & $<0.0001$ \\
\hline
\end{tabular}

SLE $=$ systemic lupus erythematosus

* $p$ values versus rheumatoid arthritis (Mann-Whitney test).

termined pleural fluid and serum levels of NSE in 342 patients with pleural effusions of various aetiologies including 17 with rheumatoid arthritis.

\section{Methods}

Pleural fluid and blood were collected from 342 patients with a newly detected pleural effusion. Since haemolysis causes an increase in the levels of NSE, patients with haemorrhagic pleural effusions were excluded. The patients were divided into the following 10 diagnostic categories: rheumatoid arthritis, in accordance with the 1987 revised criteria of the American College of Rheumatology (ACR) $(n=17$, all were seropositive with respect to rheumatoid factor and in four cases pleurisy was the first manifestation of the disease); lung cancer ( $\mathrm{n}=$ 52, 12 with small cell lung cancer); malignant mesothelioma $(n=10)$; cancer of extrapulmonary origin $(n=67)$; systemic lupus erythematosus (SLE) in accordance with the ACR criteria for the classification of SLE ( $n=$ 5); microbiologically or histologically verified tuberculosis $(n=27)$; parapneumonic effusion or pleural empyema $(n=43)$; other defined diseases $(n=22)$; exudative pleural effusion of unknown aetiology $(n=72)$; and congestive heart failure with transudative pleural effusion $(\mathrm{n}=27)$

NSE was measured with a commercially available double antibody radioimmunoassay (Pharmacia AB, Uppsala, Sweden). The statistical calculations were performed using the Mann-Whitney's test and Spearman's correlation test.

\section{Results}

The median NSE concentration in pleural fluid was higher in the effusions due to rheumatoid arthritis than in those due to any other disease (table 1). In rheumatoid arthritis NSE concentrations in the pleural fluid correlated inversely with pleural fluid concentrations of glucose (Spearman's $r=-0.49$ ) and the $\mathrm{pH}$ of the pleural fluid $(r=-0 \cdot 61)$. The median pleural fluid:serum NSE ratio was much higher in rheumatoid arthritis than in any of the other diagnoses (table 2).

Although the concentration of NSE in the pleural fluid was higher in effusions associated with small cell lung cancer (median $18 \cdot 1 \mu \mathrm{g} / \mathrm{l}$; range $1 \cdot 8-107 \cdot 6,95 \%$ confidence interval (CI) $5 \cdot 1$ to $30 \cdot 8$ ) than in other lung cancers (median $5 \cdot 4 \mu \mathrm{g} / \mathrm{l}$; range $2 \cdot 5-168 \cdot 8 ; 95 \%$ CI $4 \cdot 4$ to $7 \cdot 0 ; p=0.05$ ), it was still lower than in the 
Table 2 Pleural fluid:serum neurone-specific enolase (NSE) ratios in rheumatoid pleural effusions compared with effusions of other aetiologies

\begin{tabular}{|c|c|c|c|c|c|}
\hline Diagnosis & $n$ & Median & Range & $95 \% C I$ & $p^{*}$ \\
\hline Rheumatoid arthritis & 15 & $11 \cdot 6$ & $1 \cdot 2-81 \cdot 0$ & $3 \cdot 1$ to $24 \cdot 7$ & \\
\hline Lung cancer & 52 & 0.9 & $0 \cdot 1-21 \cdot 1$ & 0.6 to 1.1 & $<0.0001$ \\
\hline Mesothelioma & 10 & $1 \cdot 4$ & $0.2-9.9$ & 0.6 to 6.8 & $<0.005$ \\
\hline Other cancers & 66 & 0.9 & $0-12 \cdot 0$ & 0.6 to 1.1 & $<0.0001$ \\
\hline SLE & 2 & 1.9 & $0 \cdot 7-3 \cdot 2$ & - & NS \\
\hline Tuberculosis & 26 & $0 \cdot 8$ & $0 \cdot 1-10 \cdot 7$ & 0.5 to 1.7 & $<0.0001$ \\
\hline Parapneumonic effusions & 43 & $1 \cdot 0$ & $0 \cdot 2-4 \cdot 4$ & 0.7 to 1.4 & $<0.0001$ \\
\hline Other verified diagnoses & 22 & $0 \cdot 6$ & $0 \cdot 1-6 \cdot 0$ & 0.4 to 0.9 & $<0.0001$ \\
\hline Non-specific effusions & 70 & 0.9 & $0 \cdot 1-5 \cdot 7$ & 0.7 to 1.2 & $<0.0001$ \\
\hline Congestive heart failure & 27 & $0 \cdot 3$ & $0 \cdot 1-3 \cdot 6$ & 0.2 to 0.5 & $<0.0001$ \\
\hline
\end{tabular}

SLE $=$ systemic lupus erythematosus.

${ }^{*} p$ values versus rheumatoid arthritis (Mann-Whitney test).

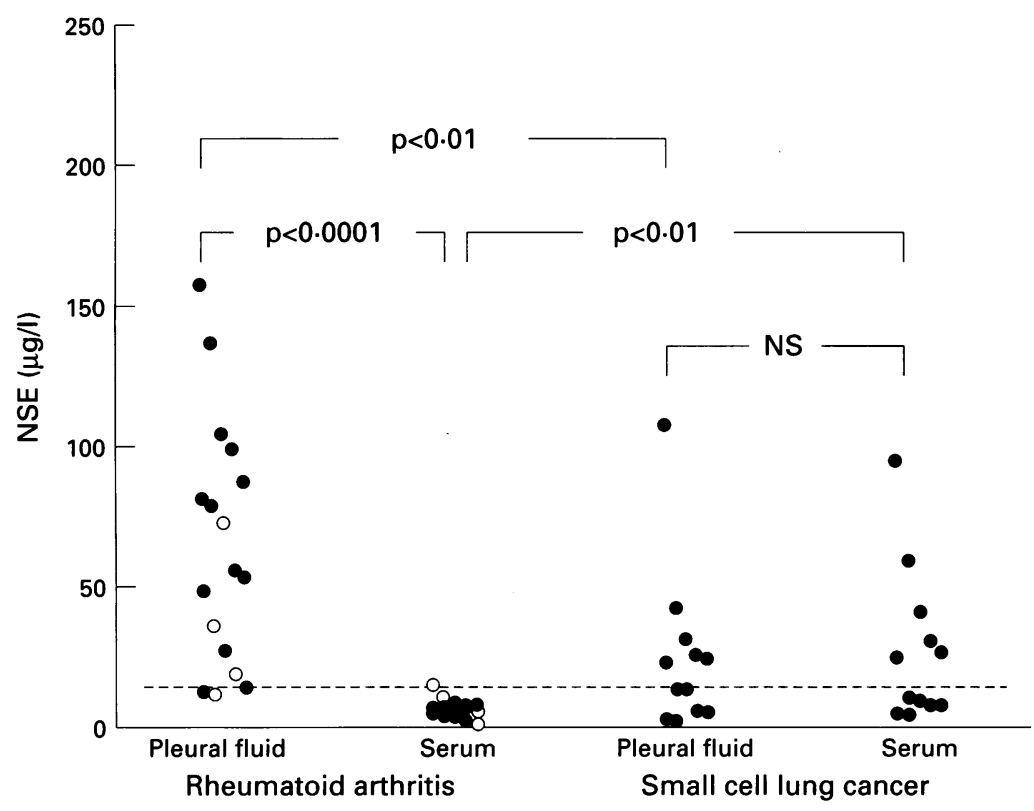

Pleural fluid and serum levels of neurone-specific enolase (NSE) in patients with rheumatoid arthritis and small cell lung cancer. Patients with pleurisy as their first manifestation of rheumatoid arthritis are indicated by open circles. Dotted line $=$ upper reference limit for serum NSE (Mann-Whitney test). those with rheumatoid arthritis from those with small cell lung cancer.

Diagnostically useful characteristics of a rheumatoid pleural effusion include a low glucose concentration, a low $\mathrm{pH}$, a high lactate dehydrogenase level, and low complement concentrations. ${ }^{6}$ However, none of these tests is sensitive and specific enough for a specific diagnosis of rheumatoid effusion, and they should be considered within the clinical context. The diagnosis of rheumatoid pleurisy may be particularly difficult when a pleural effusion is the first manifestation of rheumatoid arthritis. In the present study pleural fluid concentrations of NSE, and, particularly, the pleural fluid:serum NSE ratio, were useful for identifying patients with rheumatoid arthritis, including those without joint disease. However, we do not regard the determination of pleural fluid levels of NSE as being superior to the traditional laboratory tests used in the diagnosis of rheumatoid pleurisy.

The high pleural fluid:serum NSE ratio suggests local release and accumulation of NSE within the pleural space in rheumatoid pleurisy. Neuroendocrine cells are not found in the pleural membrane, and the neuroendocrine cells of the lung are thought to produce NSE in response to hypoxaemia. ${ }^{7}$ A low oxygen tension, high carbon dioxide tension, low glucose level, high lactate level, and low pH occur in both synovial and pleural effusions in rheumatoid arthritis, ${ }^{8-10}$ oxygen tensions of $3-6 \cdot 5 \mathrm{kPa}$ having been reported in rheumatoid pleural effusions. ${ }^{911}$ In rheumatoid pleurisy, inflammation and thickening of the pleura and local vasculitis might be the cause of this hypoxaemia and increased anaerobic glycolysis. Accumulation of the products of anaerobic glycolysis (carbon dioxide and lactate) might account for the pleural fluid acidosis. Our observation that NSE levels in rheumatoid pleural effusions correlated inversely with glucose levels and $\mathrm{pH}$ suggests some relationship between high NSE levels and anaerobic glycolysis. It is possible that the high NSE concentrations in rheumatoid pleural effusions are associated with local tissue hypoxaemia and subsequent increased anaerobic glycolysis. The pleural fluid:serum NSE ratio was much higher in rheumatoid arthritis than in small cell lung cancer (median $0 \cdot 86$; range $1 \cdot 1-10 \cdot 5 ; 95 \%$ CI 0.4 to $1.2 ; \mathrm{p}<0.01)$.

Using 2.4 as the cutoff value, the pleural fluid:serum NSE ratio had a sensitivity of $87 \%$ and a specificity of $84 \%$ for the diagnosis of rheumatoid arthritis. The specificity increased to $91 \%$ when the cancers were excluded.

\section{Discussion}

We observed remarkably high NSE concentrations in rheumatoid pleural effusions which distinguished rheumatoid pleurisy from any other non-malignant inflammatory disease and from neoplastic diseases. There was a considerable overlap in the pleural fluid concentrations of NSE between patients with rheumatoid arthritis and those with small cell lung cancer, but the significantly increased pleural fluid:serum NSE ratio differentiated
This study was supported by a grant from the Mjölbolsta Hospital Foundation for Medical Research

1 Schmechel D, Marangos P J, Brightman M. Neuron-specific enolase is a molecular marker for peripheral and central neuroendocrine cells. Nature 1978;276:834-6.

2 Marangos PJ, Schmechel D, Parma AM, Clark RL Goodwin FK. Measurement of neuron-specific (NSE) and non-neuronal (NNE) isoenzymes of enolase in rat, monkey and human nervous tissue. $\mathcal{F}$ Neurochem $1979 ; 33$ 319-29.

3 Esscher T, Steinholtz L, Bergh J, Nöu E, Nilsson K, Påhlman $S$. Neuron specific enolase: a useful diagnostic serum marker for small cell carcinoma of the lung. Thorax 1985 40:85-90.

4 Shimokata K, Niwa Y, Yamamoto M, Sasou H, Morishita M. Pleural fluid neuron-specific enolase. A useful diagnostic marker for small cell lung cancer pleurisy. Chest 1989;95: marker

5 Pettersson T, Klockars M, Fröseth B. Neuron-specific enolase in the diagnosis of small cell lung cancer with pleural effusion: a negative report. Eur Respir 7 1988;1:698-700.

6 Joseph J, Sahn SA. Connective tissue diseases and the pleura. Chest 1993;104:262-70.

7 Scheuermann DW. Neuroendocrine cells. In: Crystal RG, ed. The lung: scientific foundations. New York: Raven Press, 1991:289-99.

8 Wallis WJ, Simkin PA, Nelp WB. Low synovial clearance 
of iodide provides evidence of hypoperfusion in chronic rheumatoid synovitis. Arthritis Rheum 1985;28:1096-104. 9 Sahn SA, Kaplan RL, Maulitz RM, Good JT. Rheumatoid pleurisy. Observations on the development of low pleural pleurisy. Observations on the development of low pleural fluid $\mathrm{pH}$.
10 Taryle DA, Good JT, Sahn SA. Acid generation by pleural fluid: possible role in the determination of pleural fluid pH. $f$ Lab Clin Med 1979;93:1041-6.

pH. F Lab Clin Med 1979;93:1041-6.
11 Pettersson T, Ojala K, Weber TH. Diagnostic significance of pleural fluid lactate concentrations. Infection 1985;13: of pleural

\title{
Epidemic outbreak of interstitial lung disease in aerographics textile workers - the "Ardystil syndrome": a first year follow up
}

\author{
Amparo Solé, Pedro J Cordero, Pilar Morales, Manuela E Martínez, Francisco Vera, \\ Carmen Moya
}

Service of Pneumology A Solé

P J Cordero

$P$ Morales

M E Martínez

Service of Pathology

F Vera

La Fe University Hospital, Valencia, Spain

Conselleria de Sanitat I Consum, Generalitat Valenciana, Valencia, Spain

C Moya Reprint requests to:
Dra Amparo Solé Jover, Bélgica 26, $40^{\mathrm{a}}$ Belgica $26,40^{\mathrm{a}}$,
Valencia 46021 , Spain. Valencia 46021, Spain. Returned to authors 19 April 1995 Revised version received 26 May 1995 Accepted for publication 30 August 1995

\begin{abstract}
Background - The longer term respiratory effects of massive inhalational exposure of textile printing sprayers to Acramin (the "Ardystil syndrome") are not well established.
\end{abstract}

Methods - A 12 month follow up of 27 heavily exposed textile sprayers was performed.

Results - Twenty one patients experienced cough, 18 dyspnoea, and 17 nose bleeding at initial exposure, with histological evidence of organising pneumonia in 13 cases, radiological abnormalities detected by computed tomographic scanning in 20 cases, and diminution of diffusion capacity to below $80 \%$ of predicted in seven cases. At one year after exposure symptoms persisted in 15 cases, radiological alterations in six, and diffusion capacity was reduced in nine.

Conclusions - Whilst most of our patients showed improvement at one year, evidence of persistent lung involvement was present in an appreciable minority of exposed cases.

(Thorax 1996;51:94-95)

Keywords: occupational lung disease, interstitial lung disease.

An epidemic outbreak of interstitial lung disease occurred in textile print spraying companies in the Autonomous Community of Valencia, Spain in $1992 . .^{12}$ During that year six workers died of a restrictive pulmonary insufficiency due to organising pneumonia associated sometimes with pulmonary fibrosis, and another worker proceeded to double lung transplantation. This has been called locally the "Ardystil syndrome", after the name of the firm in which the first deaths occurred. Investigations carried out by the Public Health Department established that the lung disease was caused by spraying procedures delivering a respirable aerosol of Acramin FWIJ (a sub- stance obtained from the reaction between a diethylenetriamine and adipic acid). ${ }^{2}$ Organising pneumonia is the main pathological feature, but the pathology ranges from nonspecific (or minor) lung lesions to pulmonary fibrosis.

In the present study we report the clinical, radiological, and functional courses of patients with this syndrome followed up over a one year period.

\section{Methods}

Approximately 90 workers in the Autonomous Community of Valencia are thought to have been affected by exposure, of whom 27 (21 women), including the most severe clinical cases, were treated in our hospital. The mean (SD) age of the patients was 23 (8) years (range 17-52), and 21 were smokers. Eight of these patients were seen specifically for assessment for possible lung transplantation. Diagnosis was confirmed by transbronchial biopsy in 24 cases, videothoracoscopy in one, and at necropsy in another. In one patient the severity of the disease prevented the performance of a pulmonary biopsy. Lung abnormalities were interpreted as minor changes (increased numbers of macrophages) in six cases, intra-alveolar knots of fibrin in eight, and organising pneumonia in 13. All 27 patients were treated with oral corticosteroids.

\section{Results}

The most frequently reported symptoms at presentation were cough (21 cases), shortness of breath (18 cases), and nose bleeding (17 cases). After one year these symptoms had significantly improved in the 26 survivors with nose bleeding persisting in one patient, cough in eight, and shortness of breath in four. In addition to the respiratory symptoms, 14 patients experienced abdominal pain, diarrhoea or nausea. Cognitive disorders (memory loss) and minor neurological manifestations (head- 